\title{
Explaining global job satisfaction by facets of job satisfaction: the Japanese civil servants study
}

\author{
Takashi Tatsuse $\cdot$ Michikazu Sekine
}

Received: 25 April 2010/Accepted: 20 July 2010/Published online: 14 August 2010

(C) The Japanese Society for Hygiene 2010

\begin{abstract}
Objectives Management of job satisfaction is of growing importance in terms of the maintenance of employees' health. This study aimed to evaluate which and to what extent facets of job satisfaction contributed to global job satisfaction.

Methods The participants were 4286 employees aged 18-69 years working in local government in Japan. A questionnaire survey was conducted in 1998-1999. Seven facets of job satisfaction were evaluated. Multiple logistic regression analysis was performed to evaluate which facets of job satisfaction contributed to global job satisfaction.

Results For all employees, all of the facets of job satisfaction significantly contributed to global job satisfaction. Among the facets of job satisfaction, 'being satisfied with interests and skills involved in work' and 'how abilities were used' contributed more strongly to global satisfaction than 'being satisfied with how the section is running', 'co-workers', 'work prospects', 'physical working conditions' and 'payment'. The differing associations of facets of job satisfaction with global job satisfaction did not change substantially in stratified analysis by occupation, with one exception that only three facets of job satisfaction contributed to global job satisfaction in administrative workers.

Conclusion Job satisfaction related to the intrinsic aspects of the job (i.e., 'interests and skills involved in work' and 'how abilities were used') contributed more to global job satisfaction than the other aspects of job
\end{abstract}

T. Tatsuse $(\bowtie) \cdot$ M. Sekine

Department of Welfare Promotion and Epidemiology,

Graduate School of Medicine and Pharmaceutical Sciences, University of Toyama, 2630 Sugitani, Toyama 930-0194, Japan

e-mail: tatsuse@med.u-toyama.ac.jp satisfaction. Longitudinal research in employees with various occupations may be needed to confirm the results of this study.

Keywords Job satisfaction - Occupation - Working environments · The JACS study · Japan

\section{Introduction}

Many people spend a considerable proportion of their waking hours at work. If workers are dissatisfied with their jobs, their health may deteriorate. The findings from a meta-analysis indicate that job dissatisfaction is associated with mental health problems such as burnout, low selfesteem, depression, and anxiety [1]. Although the associations of job satisfaction with physical health remain inconclusive [1-3], job dissatisfaction has been linked to coronary heart disease (CHD) and mortality from CHD $[4,5]$. In addition, job satisfaction was often found to be associated with perceived locus of control, job turnover, and early retirement $[3,6]$.

When we looked at changes in working environments from a global economic perspective, recent on-the- job conditions have worsened (e.g., slow economic growth, organizational restructuring, and wage cuts). Meanwhile, work practices are becoming more automated and inflexible, leaving employees with less control over their work stress. It is therefore important for employees to not only reduce their levels of job stress, but also to increase their degree of job satisfaction. In addition, in order to improve employees' global job satisfaction, organizations may need to identify which facets of job satisfaction have more influence over employees' global job satisfaction. Of note, previous studies about whether facets of job satisfaction 
contributed to global satisfaction differed among age, sex, and occupations and were not consistent $[2,7]$.

This study aimed to evaluate which and to what extent facets of job satisfaction contributed to global job satisfaction and whether the associations of facets of job satisfaction with global job satisfaction differed among a Japanese civil servant population.

\section{Methods}

\section{Study subjects}

The Japanese civil servants study (the JACS study) is an international collaborative study with a British civil servants study (the Whitehall II study) [8, 9]. Phase I of the JACS study was conducted between 1998 and 1999. The subjects of this study were all civil servants, aged 18-69 years at the time of survey, working in local government located on the west coast of Japan. The subjects consisted mainly of administrative workers, professional workers (technicians, teachers, and hospital workers), clerical workers, and office support staff. A questionnaire was sent to the participants, through the personnel section of the civil service. After filling in the questionnaire, subjects returned it in a sealed envelope. The total population was 6090 . Four thousand nine hundred thirty-three subjects responded to the questionnaire (response rate 81.0\%). Subjects who did not answer one or more questions about age, sex, job type, work hours per day, and job satisfaction were excluded from the analysis. Finally, data for 4286 subjects (2949 men and 1337 women) were analyzed. The mean ages of the subjects were 42.3 years (SD: 10.0) for men and 39.3 (SD: 10.8) for women.

This study was conducted as a part of the annual health checkups regulated by the Japanese Industrial Safety and Health Law. An ad hoc committee of the civil service, comprising an ordinary member of the Safety and Health Committee, and labor and personnel representatives, approved the contents and ethical aspects of this study. Informed consents were obtained from all participants, who all took part in the study voluntarily.

\section{Measures}

The questionnaire items for job satisfaction were chosen from those used in the Whitehall II study [10]. The English questionnaire was translated into Japanese and then translated back into English by a person who had no knowledge of the original English questionnaire. The back-translated questionnaire was then compared with the original version by researchers from the Whitehall II study.
The scale of facets of job satisfaction consists of 7 questions, asking participants to rate their satisfaction with: take home pay; work prospects; co-workers; physical working conditions; how their section is run; how one's abilities are used; and the interest and skill involved in the job. To assess global satisfaction, the questionnaire also asked about "job as a whole taking everything into consideration." For each question, participants rated their job satisfaction according to one of 4 response categories, consisting of "very satisfied", "satisfied", "dissatisfied", and "very dissatisfied" [11]. Defined as an attitude, job satisfaction is "a positive or negative evaluative judgment one makes about one's job or job situation" [12]. All the job satisfaction scales were dichotomized into "satisfied" or "dissatisfied" for analysis.

With respect to working hours, the subjects were asked to answer how many hours a day they had worked in the past month.

\section{Statistical analysis}

We conducted $\chi^{2}$ tests to evaluate whether there were differences in global job satisfaction according to sex, age, occupation, and working hours. A fourfold point correlation [phi $(\varphi)$ coefficient] was calculated to evaluate correlations between global satisfaction and facets of satisfaction. Multiple logistic regression analysis was performed to evaluate which facets of job satisfaction contributed to global job satisfaction. We employed a stepwise forward selection method to select out variables. A $p$ value of less than 0.05 was used as the criterion for the inclusion of a variable into the model. Odds ratios (ORs) and 95\% confidence intervals were calculated to evaluate the strength of contribution of each facet of job satisfaction to global satisfaction. The coefficient of determination, Nagelkerke $R^{2}$, a factor that indicates the explanatory quality of a model, was also computed [13]. Stratified analysis by age, sex, and occupation was also performed. Statistical analyses were performed using SPSS software (10.0J) (SPSS, Chicago, IL, USA).

\section{Results}

Table 1 shows the characteristics of the subjects and the proportion of those who were satisfied with their jobs as a whole. Approximately two-thirds of the subjects were satisfied with their jobs as a whole. Men, those aged less than 25 or over 45 years, and administrative and office support workers and those who worked less than or equal to $8 \mathrm{~h}$ a day on average were more likely to be satisfied with their jobs (more than 65\% satisfied). All of the facet variables were significantly related to the global job 
Table 1 Characteristics of the subjects and proportions of those showing global satisfaction

\begin{tabular}{|c|c|c|c|}
\hline & $\begin{array}{l}\text { Subjects } \\
(N=4286)\end{array}$ & $\begin{array}{l}\text { People showing } \\
\text { global satisfaction }(\%)\end{array}$ & $\overline{\chi^{2} p \text { value }}$ \\
\hline \multicolumn{4}{|l|}{ Sex } \\
\hline Men & 2949 & 66.4 & \\
\hline Women & 1337 & 60.4 & $<0.001$ \\
\hline \multicolumn{4}{|l|}{ Age, years } \\
\hline $18-24$ & 219 & 65.8 & \\
\hline $25-34$ & 1140 & 62.0 & \\
\hline $35-44$ & 1152 & 58.6 & \\
\hline $45-54$ & 1338 & 68.3 & \\
\hline $55-69$ & 437 & 74.8 & $<0.001$ \\
\hline \multicolumn{4}{|l|}{ Job type } \\
\hline Administrative & 231 & 83.1 & \\
\hline Professional & 2164 & 62.8 & \\
\hline Clerical & 1460 & 63.2 & \\
\hline Office support & 431 & 67.7 & $<0.001$ \\
\hline \multicolumn{4}{|l|}{ Work hours } \\
\hline$\leqq 8 \mathrm{~h}$ & 2035 & 67.7 & \\
\hline $8-9 \mathrm{~h}$ & 1185 & 64.3 & \\
\hline $9-11 \mathrm{~h}$ & 727 & 59.4 & \\
\hline$>11 \mathrm{~h}$ & 339 & 57.5 & 0.001 \\
\hline
\end{tabular}

Pearson's $\chi^{2}$ tests were used to examine whether there were differences in the proportions of subjects with global job satisfaction and those with global job dissatisfaction

satisfaction variable $(p<0.001$ for all correlation coefficients): $\varphi$ coefficient $=0.62$ for 'interest and skill involved'; 0.62 for 'how abilities are used'; 0.52 for 'how section is run'; 0.45 for 'work prospects'; 0.43 for 'co-workers'; 0.42 for the 'physical working conditions'; and 0.29 for 'payment'.

Table 2 shows the results of multiple logistic regression analysis of the contribution of facets of job satisfaction to global job satisfaction. In the multivariate model for all workers, the variables chosen by the stepwise method accounted for $67.9 \%$ of the variance in global job satisfaction, and all facets of job satisfaction variables significantly contributed to the global job satisfaction variable. The variables of 'interest and skill involved' and 'how abilities are used' showed relatively high contributions, with ORs of 7.25 and 4.37 , respectively. These variables were followed by the variables, 'work prospects' with OR 3.02, 'co-workers' with OR 3.01, and 'how section is run' with OR 2.48. ORs for the variables of 'physical working conditions' and 'payment' were relatively small, at 2.05 and 1.71 , respectively.

In the models by occupation, the variables of age and work hours were associated with global job satisfaction for some occupations. Among clerical workers, the coefficient of determination $\left(R^{2}\right)$ was $70.7 \%$, the largest of all occupations. That of administrative workers was $64.8 \%$, though only three items of facets of job satisfaction were selected, 'interest and skill involved', 'how abilities are used', and 'co-workers'. The item 'payment' was selected in the models of the professional and the clerical workers.

In the models by age and sex, the contribution to global satisfaction of facet satisfaction showed the same trend as that in the all workers model.

\section{Discussion}

In the present study, all seven of the facet items contributed to global job satisfaction, with relatively stronger contributions of 'interest and skill involved' and 'how abilities are used'. Sex was not selected. Age and work hours also contributed significantly to global satisfaction, but the contribution of these factors was small compared to the facet factors of job satisfaction. So, global satisfaction may be dependent largely on the intrinsic aspects of work rather than on other aspects of the job, age, and sex.

The two facets of job satisfaction that had higher contributions, 'interest and skill involved' and 'how abilities are used' correspond with the intrinsic factors argued in the two-factor theory [14]. The factors that had smaller contributions, 'physical working conditions' and 'payment', are considered to be extrinsic factors. There is some evidence that intrinsic aspects of job characteristics; that is, the "nature of work itself", have a greater contribution to global job satisfaction than other job facets. The findings of the present study are consistent with those of previous studies $[14,15]$.

In addition, this study showed that the different kinds of factors contributing to global satisfaction that were observed in stratified analysis by occupation, and the pattern of the relative contribution did not differ among occupations (i.e., intrinsic factors contributed more than extrinsic factors). Regarding the kind of contributing factors, professional work followed almost the same trend as that in the all workers model, as did clerical work. In office support work, associations were not found among facet factors (physical working conditions and payment). In administrative work, not only were the three facets of job satisfaction selected but also the contributions of these factors were very high compared to other occupations.

The difference in associated factors among workers engaged in administrative work, supportive work, and other types of work can be estimated by examining the fact that the degree of contribution of facet factors differs by occupation. In administrative work, only three facets of job satisfaction were selected. This happened either because the excluded factors had no association with job satisfaction, or because these factors were satisfied at levels too 
Table 2 Association between global job satisfaction and facets of job satisfaction

\begin{tabular}{|c|c|c|c|c|c|c|c|c|c|c|}
\hline & \multirow{2}{*}{\multicolumn{2}{|c|}{$\begin{array}{l}\text { All workers } \\
(N=4286) \\
\text { OR }(95 \% \mathrm{CI})\end{array}$}} & \multirow{2}{*}{\multicolumn{2}{|c|}{$\begin{array}{l}\text { Administrative } \\
(N=231) \\
\text { OR }(95 \% \mathrm{CI})\end{array}$}} & \multirow{2}{*}{\multicolumn{2}{|c|}{$\begin{array}{l}\text { Professional } \\
(N=2164) \\
\text { OR }(95 \% \mathrm{CI})\end{array}$}} & \multirow{2}{*}{\multicolumn{2}{|c|}{$\begin{array}{l}\text { Clerical } \\
(N=1460) \\
\text { OR }(95 \% \mathrm{CI})\end{array}$}} & \multirow{2}{*}{\multicolumn{2}{|c|}{$\begin{array}{l}\text { Office support } \\
(N=431) \\
\text { OR }(95 \% \mathrm{CI})\end{array}$}} \\
\hline & & & & & & & & & & \\
\hline \multicolumn{11}{|l|}{ Age, years } \\
\hline-34 & 1.00 & & - & & 1.00 & & 1.00 & & - & \\
\hline $35-44$ & 1.31 & $(1.02-1.68)$ & & & 1.21 & $(0.86-1.70)$ & 1.47 & $(0.97-2.23)$ & & \\
\hline $45-69$ & 1.61 & $(1.27-2.04)$ & & & 1.62 & $(1.18-2.23)$ & 1.82 & $(1.17-2.81)$ & & \\
\hline Work hours & 1.12 & $(1.01-1.24)$ & - & & - & & 1.34 & $(1.12-1.61)$ & - & \\
\hline \multicolumn{11}{|c|}{ Facets of job satisfaction (vs. being dissatisfied) } \\
\hline Interest and skill involved & 7.25 & $(5.93-8.86)$ & 8.20 & $(2.78-24.28)$ & 7.39 & $(5.61-9.72)$ & 7.52 & $(5.17-10.94)$ & 7.10 & $(3.77-13.37)$ \\
\hline How abilities are used & 4.37 & $(3.55-5.38)$ & 15.48 & $(5.13-46.74)$ & 4.27 & $(3.20-5.70)$ & 4.49 & $(3.11-6.48)$ & 4.09 & $(2.10-7.97)$ \\
\hline How section is run & 2.48 & $(2.00-3.07)$ & - & & 2.18 & $(1.62-2.95)$ & 3.06 & $(2.12-4.43)$ & 3.09 & $(1.57-6.08)$ \\
\hline Physical working conditions & 2.05 & $(1.67-2.51)$ & - & & 2.22 & $(1.68-2.93)$ & 1.89 & $(1.32-2.70)$ & - & \\
\hline Co-workers & 3.01 & $(2.43-3.74)$ & 4.23 & $(1.48-12.09)$ & 2.87 & $(2.14-3.84)$ & 4.19 & $(2.80-6.29)$ & 2.32 & $(1.20-4.47)$ \\
\hline Work prospects & 3.02 & $(2.42-3.76)$ & - & & 2.71 & $(2.01-3.66)$ & 3.47 & $(2.35-5.13)$ & 5.64 & $(2.38-13.37)$ \\
\hline Payment (take-home pay) & 1.71 & $(1.39-2.09)$ & - & & 2.15 & $(1.63-2.85)$ & 1.51 & $(1.06-2.11)$ & - & \\
\hline$R^{2}$ & \multicolumn{2}{|c|}{$67.9 \%$} & \multicolumn{2}{|l|}{$64.8 \%$} & \multicolumn{2}{|c|}{$66.9 \%$} & \multicolumn{2}{|c|}{$70.7 \%$} & \multicolumn{2}{|c|}{$65.6 \%$} \\
\hline
\end{tabular}

Multiple logistic regression models: significant variables were identified through a stepwise method

Input indicators are predictor variables: sex, age, work hours, and each facet of job satisfaction

$O R$ odds ratio, $C I$ confidence interval, $R^{2}$ coefficient of determination

high to judge [10]. One hypothesis is that, in general, workers in an administrative section are required to have the ability to manage an organization. In addition, 'work prospects' and 'payment' did not relate to their job satisfaction. It is possible that these standards may have already been at a high level in this job type. In the professional workers model, 'interest and skill involved' was shown to have a strong association with global satisfaction, whereas in the office support workers model, the facet of 'work prospects' showed a relatively strong association in each occupation. These results seem to reflect a specific feature of occupations that have a career path [3]. Our study is unable to provide contexts of why particular job satisfaction facets had greater/weaker contribution to global job satisfaction by occupation. Still, these differences indicated a different degree of contribution by occupation, so, their appearance in this study is important in light of management concerns.

This study has several methodological limitations. Firstly, subjects were limited to groups of public servants. These groups may already have higher satisfaction in some facets of job satisfaction. It is well known that payment to Japanese civil servants is stable and higher when compared to that of private sector employees [16]. Therefore, the association of payment satisfaction with global satisfaction may be underestimated, but results did indicate that the impact of payment among the general population was small nonetheless [2]. Additionally, the range of occupations may be small in the group in our study. It is considered that our subjects were similar to one another in working conditions compared to the private sector; therefore, the difference in contribution by occupation may be much larger in the general adult population. The direct generalization of these results to the respective occupations should be treated cautiously.

Secondly, other facets associated with global job satisfaction may exist. Previous studies pointed out that communication and job security were associated with job satisfaction [2]. In addition, other psychosocial factors, such as job stress or work-family conflicts, may affect job satisfaction. However, even if correlations were present, these elements were seen as differentiated from the facets of job satisfaction in terms of worker management [7]. Moreover, the explanatory quality of each model in the present study was as high as more than approximately $65 \%$ [17].

Thirdly, our study design was cross-sectional, and causal judgments are not warranted. Longitudinal studies are needed to confirm the direction of the found associations.

In conclusion, the facet aspects of job satisfaction greatly contributed in total to global job satisfaction. Although the relative contribution of facet satisfaction to global satisfaction differed among occupations, 'interest and skill involved' and 'how abilities are used' showed robust associations with global job satisfaction regardless of occupation. Although longitudinal research in employees with various occupations may be needed to confirm the results of this study, from a management perspective, the 
effect of aspects of the job itself on job satisfaction should be more emphasized to improve occupational health in the Japanese population. In addition, this study also indicates the utility of the seven facets of job satisfaction if applied to measures to improve job satisfaction in each of the study occupations.

Acknowledgments We are indebted to the members of the personnel section of the local government who took part in and cooperated in this study and all the civil servants in that local government who participated in this study. This study was in part funded by the Ministry of Health, Labour and Welfare of Japan, the Japanese Society for the Promotion of Science, the Occupational Health Promotion Foundation, the Univers Foundation (98.04.017), the Daiwa Anglo-Japanese Foundation (03/2059), and the Great Britain Sasakawa Foundation (2551). Funding organizations were not involved in the design, conduct, interpretation, or analysis of the study, or in the review or approval of the manuscript.

\section{References}

1. Farager EB, Cass M, Cooper CL. The relationship between job satisfaction and health: a meta-analysis. Occup Environ Med. 2005;62:105-12.

2. Spector PE. Job satisfaction: application, assessment, causes, and consequences. Thousand Oaks: SAGE Publications; 2010.

3. Rees D, Cooper CL. Occupational stress in health service workers in the UK. Stress Med. 1992;8:79-90.

4. Hemingway H, Marmot M. Evidence based cardiology: psychosocial factors in the aetiology and prognosis of coronary heart disease: systematic review of prospective cohort studies. BMJ. 1999;318:1460-7.

5. Sales SM, House J. Job dissatisfaction as a possible risk factor in coronary heart disease. J Chronic Dis. 1971;23:861-73.

6. Mein G, Martikainen P, Stansfeld SA, Brunner EJ, Fuhrer R, Marmot M. Predictors of early retirement in British civil servants. Age Ageing. 2000;29:529-36.
7. Kristensen TS, Hannerz H, Høgh A, Borg V. The Copenhagen Psychosocial Questionnaire: a tool for the assessment and improvement of the psychosocial work environment. Scand J Work Environ Health. 2005;31:438-49.

8. Sekine M, Chandola T, Martikainen P, Lahelma E, Marmot M, Kagamimori S. Socioeconomic inequalities in physical and mental functioning of Japanese civil servants: explanations from work and family characteristics. Soc Sci Med. 2006;63:430-45.

9. Sekine M, Chandola T, Martikainen P, Marmot M, Kagamimori $\mathrm{S}$. Socioeconomic inequalities in physical and mental functioning of British, Finnish, and Japanese civil servants: role of job demand, control, and work hours. Soc Sci Med. 2009;69: $1417-25$.

10. Marmot MG, Smith GD, Stansfeld S, Patel C, North F, Head J, et al. Health inequalities among British civil servants. Lancet. 1991;337:1387-93.

11. Ferrie JE, Shipley MJ, Newman K, Stansfeld SA, Marmot M. Self-reported job insecurity and health in the Whitehall II study: potential explanations of the relationship. Soc Sci Med. 2005;60: 1593-602.

12. Weiss HM. Deconstructing job satisfaction: separating evaluations, beliefs and affective experiences. Human Resourc Manag Rev. 2002;12(2):173-94.

13. Nagelkerke NJD. A note on a general definition of the coefficient of determination. Biometrika. 1991;78:691-2.

14. Warr P, Cook J, Wall T. Scales for the measurement of some work attitudes and aspects of psychological well-being. J Occup Psychol. 1979;52:129-48.

15. Kinicki AJ, McKee-Ryan FM, Schriesheim CA, Carson KP. Assessing the construct validity of the job descriptive index: a review and meta-analysis. J Appl Psychol. 2002;87:14-32.

16. Kawasaki K, Nagashima S. What effects do the high salaries for local public employment have on the regional economy in Japan? Gov Auditing Rev. 2007;36:107-23.

17. Sousa-Poza A, Sousa-Poza AA. Well-being at work: a crossnational analysis of the levels and determinants of job satisfaction. J Soc Econ. 2000;29:517-38. 